
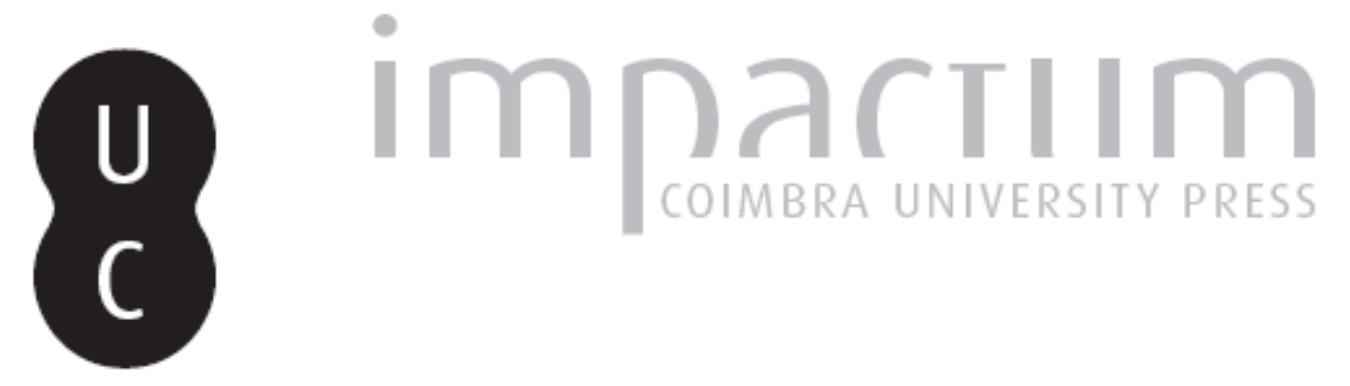

\title{
Contrastes topoclimáticos no espaço urbano e periurbano de Mangualde (Portugal): o campo termohigrométrico e o vento
}

Autor(es): $\quad$ Melo, Hugo Miguel; Ganho, Nuno

Publicado por: $\begin{aligned} & \text { Faculdade de Letras da Universidade de Coimbra, Departamento de } \\ & \text { Geografia }\end{aligned}$

URL

persistente:

URI:http://hdl.handle.net/10316.2/30255

DOI: $\quad$ DOI:http://dx.doi.org/10.14195/0871-1623_32_23

Accessed : $\quad$ 26-Apr-2023 00:33:40

A navegação consulta e descarregamento dos títulos inseridos nas Bibliotecas Digitais UC Digitalis, UC Pombalina e UC Impactum, pressupõem a aceitação plena e sem reservas dos Termos e Condições de Uso destas Bibliotecas Digitais, disponíveis em https://digitalis.uc.pt/pt-pt/termos.

Conforme exposto nos referidos Termos e Condições de Uso, o descarregamento de títulos de acesso restrito requer uma licença válida de autorização devendo o utilizador aceder ao(s) documento(s) a partir de um endereço de IP da instituição detentora da supramencionada licença.

Ao utilizador é apenas permitido o descarregamento para uso pessoal, pelo que o emprego do(s) título(s) descarregado(s) para outro fim, designadamente comercial, carece de autorização do respetivo autor ou editor da obra.

Na medida em que todas as obras da UC Digitalis se encontram protegidas pelo Código do Direito de Autor e Direitos Conexos e demais legislação aplicável, toda a cópia, parcial ou total, deste documento, nos casos em que é legalmente admitida, deverá conter ou fazer-se acompanhar por este aviso.

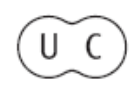




\title{
Contrastes topoclimáticos no espaço urbano e periurbano de Mangualde (Portugal) - 0 campo termohigrométrico e o vento
}

\author{
Hugo Miguel Melo \\ Mestre em Geografia Física, Ambiente e Ordenação do Território pela Faculdade de Letras da Universidade de Coimbra. \\ hugo86melo@hotmail.com
}

\section{Nuno Ganho}

Departamento de Geografia e Centro de Estudos de Geografia e Ordenamento do Território (CEGOT). Faculdade de Letras da Universidade de Coimbra. nganho@netvisao.pt

\section{Resumo}

O clima local, nem sempre foi adequadamente considerado no ordenamento urbano, pode assumir particular importância em cidades que, embora não sendo de grandes dimensões, se localizam num contexto de topografia não muito acidentada, como é o caso de Mangualde (Portugal). Neste sentido, efectuaram-se observações itinerantes de temperatura, de humidade relativa e de direcção e velocidade do vento, contemplando um conjunto de 49 locais do espaço urbano e periurbano de Mangualde, criteriosamente escolhidos em função de factores como a topografia e o tipo e características de ocupação do solo. Os resultados obtidos evidenciam campos termohigrométricos e de vento com significativos contrastes espaciais das variáveis climáticas. Neste trabalho analisam-se as duas situações, uma estival e a outra invernal, do conjunto de observações efectuadas, em que a distribuição espacial das variáveis climáticas apresentou os maiores contrastes locais.

Palavras-chave: Contrastes topoclimáticos. Ordenamento urbano. Mangualde.

\section{Résumé:}

Contrastes topoclimtiques dans les zones urbaines et périurbaines de Mangualde (Portugal) - Les camp thermohygromètrique et le vent

Le climat local n'est pas toujours suffisamment pris en compte dans la planification urbaine, peut être particulièrement important dans les villes, bien que pas très grande, sont situés dans un contexte de topographie très accidentée n'a pas, comme c'est le cas de Mangualde (Portugal). En ce sens, nous avons fait des observations de température itinérants, l'humidité relative et la vitesse et direction du vent, comprenant un ensemble de 49 Mangualde urbains et suburbains locaux, soigneusement sélectionnés en fonction de facteurs comme la topographie et le type et les caractéristiques de l'utilisation des terres. Les résultats montrent des contrastes spatiaux significatifs de variables climatiques. Dans ce papier, nous analysons les deux situations, en été et en hiver, l'ensemble des observations, dans lequel la distribution spatiale des variables climatiques a montré les plus hautes contrastes locaux.

Mots-clés: Contrastes topoclimatiques. Planification urbaine. Mangualde.

\section{Abstract:}

Topoclimate contrasts in the urban and periurban areas of Mangualde (Portugal) - The therhygrometer and the wind field

The local climate is not always adequately considered in urban planning, may be particularly important in cities, although not large, are located in a context of very rugged topography does not, as is the case of Mangualde (Portugal). In this sense, we have made itinerant observations of temperature, relative humidity and wind speed and direction, comprising a set of 49 local urban and suburban Mangualde, carefully selected according to factors such as topography and the type and characteristics of land use. The results show thermohygrometer and wind fields with significant spatial contrasts of climate variables. In this paper we analyze the two situations, one in summer and one in winter, the set of observations, in which the spatial distribution of climatic variables showed the highest local contrasts.

Keywords: Topoclimate contrasts. Urban planning. Mangualde. 


\section{Introdução}

A preocupação com as questões climáticas e a procura de uma melhoria da qualidade de vida da população, sempre foram uma constante inerente às civilizações. A climatologia urbana, como ciência explicativa dos fenómenos climáticos à escala local, teve o seu início em 1818, com o estudo realizado por Howard (1818), onde evidenciou que as temperaturas no interior do núcleo urbano de Londres eram mais elevadas que a sua envolvência (GANHO, 1998).

Desde aí estes estudos proliferaram por cidades de todo o mundo (GANHO, 1999) e em algumas de Portugal (Alcoforado, 1988). Este que aqui se apresenta trata-se de um estudo de climatologia urbana, numa área do interior do país, onde se localiza a cidade de Mangualde (Melo, 2011). Hoje, a importância da climatologia numa visão sistémica do planeamento, consagra a cidade como um sistema aberto em que a energia, a massa e os fluxos interagem de forma complexa. Importa, assim, garantir a sustentabilidade, a eficiência e a qualidade do ambiente e de vida nos meios urbanos (Marques, Ganho, Cordeiro, 2008, 2009). Actualmente, a falta de rigor numa política de ordenamento climático (Alcoforado, 1999; Alcoforado e VIEIRA, 2004), dos espaços urbanos, associada a necessidades cada vez mais exigentes, podem, de forma irreversível, causar constrangimentos económicos, sociais, ambientais e psicológicos às populações residentes nestas áreas.

Às cidades como aglomerados de modificação de energia e de produção de calor, correspondem temperaturas mais elevadas que a sua envolvência (GANHO, 1998), formando-se, regularmente, no seu interior, a chamada ilha de calor, o melhor exemplo documentado de uma modificação climática induzida pelo Homem (OKE, 1987).

Com este estudo, pretendeu-se analisar e avaliar a espacialidade dos contrastes térmicos, higrométricos e de vento na cidade de Mangualde, a uma escala local. Nesse sentido, através do estudo da atmosfera urbana inferior (urban canopy layer), pretende-se compreender a distribuição diferencial das variáveis climáticas, relacionando-as com os factores climáticos intervenientes e explicativos da sua variação e do seu comportamento, tanto para a época invernal, como para a época estival.

\section{2. Área de estudo}

A cidade de Mangualde é uma cidade pequena no contexto nacional (Figura 1), situada no centro de Portugal (NUT III Dão Lafões). Comemorou no ano transacto 25 anos da sua elevação a cidade. A sua localização insere-se na plataforma inclinada da Beira
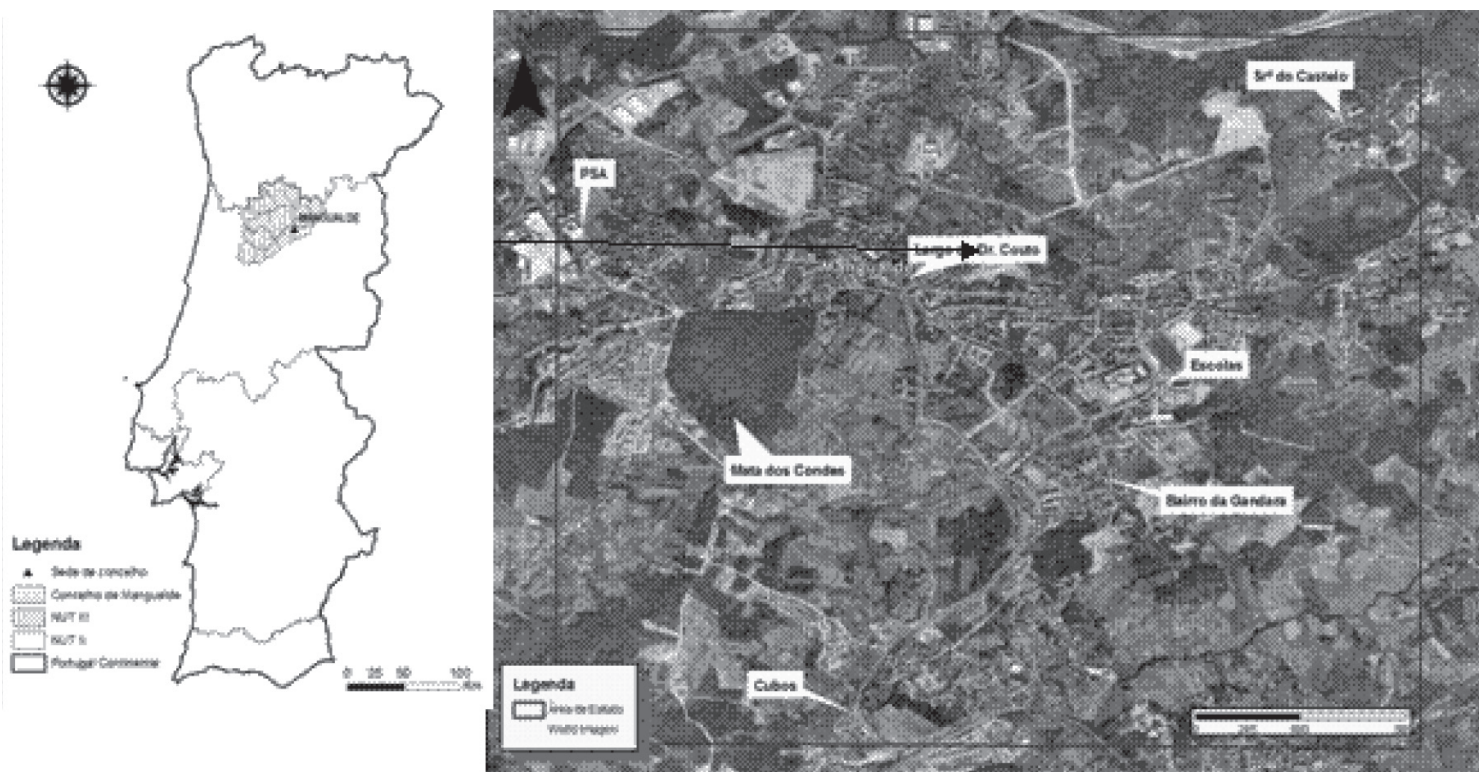

Figura 1

Portugal Continental

Fonte: Atlas do Ambiente
Figura 2

Cidade de Mangualde

Fonte: Google Earth 
Alta (O. Ribeiro, 1949), ou também chamada de plataforma do Mondego (Ferreira, 1978). Desenvolve-se no Maciço Hespérico, situa-se entre os blocos levantados do Caramulo, a Oeste, e a Cordilheira Central, a Sul. É uma área aplanada e granítica, apresentando uma ondulação ponteada por afloramentos graníticos. Geomorfologicamente, o Monte da Senhora do Castelo, com 628 metros de altitude, é uma protuberância que se soergue no sector Nordeste da cidade de Mangualde. Destacando-se da paisagem aplanada, tem uma vista privilegiada sobre toda a plataforma. Os rios Mondego e Dão, com os seus vales profundos, limitam o concelho a Sul e a Norte, estando ocupado, no caso do vale do Rio Dão, por uma albufeira com génese na Barragem de Fagilde. Já em construção, a Barragem de Girabolhos, no Rio Mondego, formará a Sul, uma segunda albufeira no concelho de Mangualde.

A sua malha urbana teve um crescimento rápido, essencialmente nos anos noventa, e atualmente esse crescimento abrandou. No entanto, as marcas de um crescimento rápido e horizontal resultaram num uso do solo heterogéneo, onde os espaços intersticiais se desenvolvem com frequência e com uma ocupação variada, dificultado a definição e, em alguns casos, a verificação dos contrastes topoclimáticos (Figura 2).

A cidade de Mangualde tem um clima do tipo temperado mediterrâneo (CSa) segundo a classificação de Koppen. É caracterizado por um Verão temperado e seco, e pela concentração da precipitação nos meses de Inverno e Primavera, nomeadamente Novembro, Dezembro, Janeiro, Fevereiro, Março e Abril. 0 índice Xerotérmico de Gaussen em que Mangualde se insere é designado por Mesomediterrâneo atenuado (ALCOFORADo, Alegria, Ramos Pereira, Sirgado, 2009).

As características do clima regional de Mangualde, dependem, primeiramente, da latitude, altitude e contexto topográfico envolvente, mas também, da sua relativa interioridade em relação à faixa costeira atlântica, conferindo-the um rigor climático superior à das cidades litorais.

Com uma população residente, no ano de 2011, de cerca de 19900 habitantes, o concelho de Mangualde teve um decréscimo demográfico de 5,3\% em relação à população de 2001, onde a população residente era de, sensivelmente, 21000 habitantes.

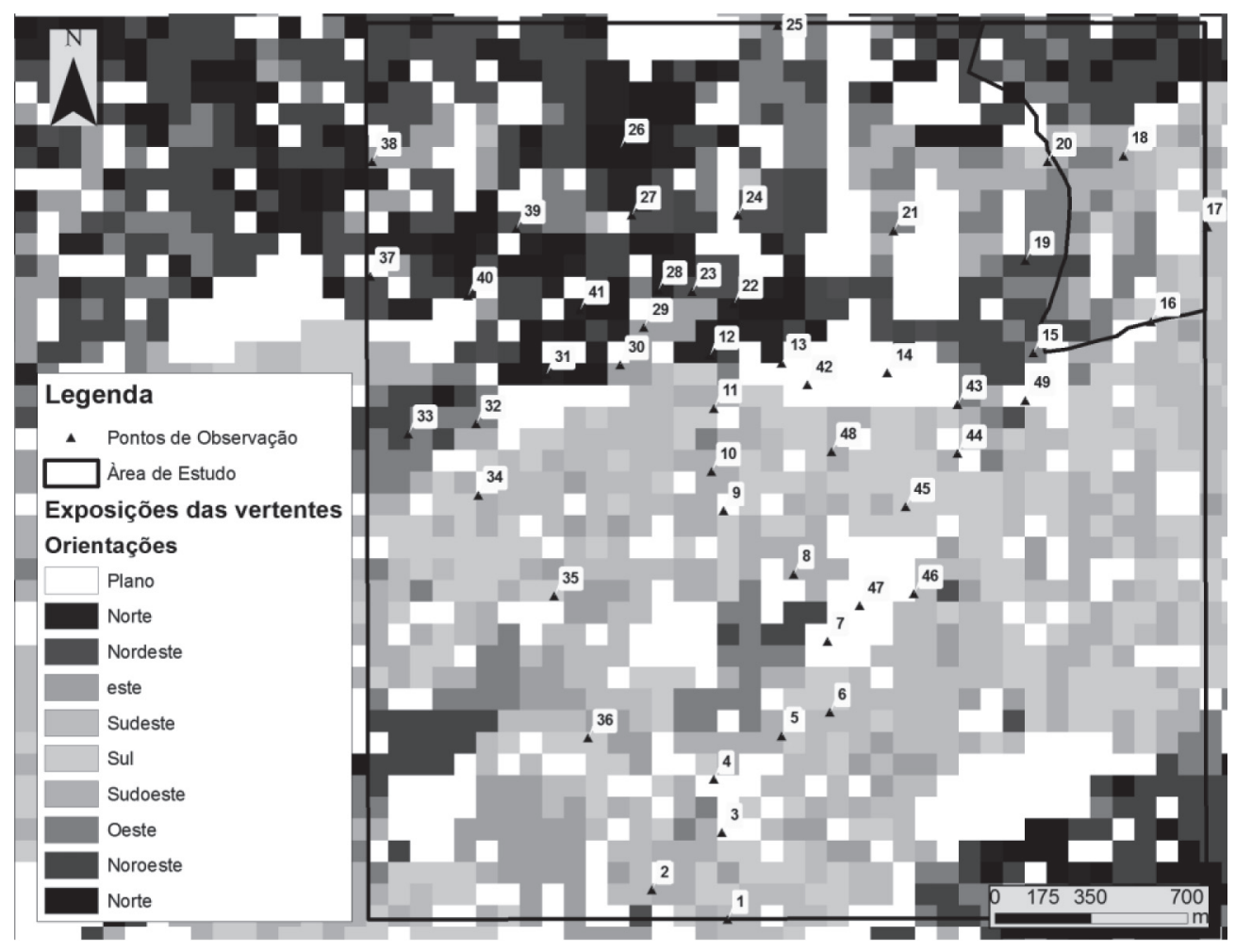

Figura 3

Exposição de vertentes na cidade de Mangualde

Fonte: Cartas altimétricas 189 e 190 


\section{Metodologia}

A análise, ainda que estiola, da realidade topoclimática, assume carácter imprescindível na definição dos contrastes termohigrométricos e do vento, a uma escala de grande pormenor. 0 protagonismo principal das variáveis temperatura, humidade relativa e vento, na interacção com os factores climáticos altitude, exposição das vertentes (Figura 3), declives (Figura 4), malha urbana, uso do solo (Figura 5) e topografia (Figura 6), resulta numa mistura de contrastes que, na submersão da realidade são difíceis de decifrar. Na realização deste estudo, e pela escassez de meios, as observações itinerantes foram a solução encontrada GANHO, 1995a, 1995b, 1995c). Num total de dez observações efectuadas, cinco de Inverno e cinco de Verão, foram escolhidas as duas com os maiores contrastes termohigrométricos e de vento, uma para a época invernal e outra para a época estival (Quadro I). Foram definidos 49 pontos de observação por toda a área de estudo (Quadro II), onde se realizaram as observações que, no máximo, entre o primeiro e o último ponto, demoravam uma hora a efectuar. Utilizando um termohigrometro sonda e uma estação meteorológica portátil, registaram-se os valores das variáveis climáticas referidas, os dados obtidos foram tratados posteriormente em ambiente SIG (kriging). Ao longo de quatro percursos de observação, completados entre as $00 \mathrm{~h}$ e a $01 \mathrm{~h}$ locais, para minorar a intervenção do factor tempo sobre o comportamento das variáveis em observação.

\section{Condições sinópticas dos dias das observações}

As circulações anticiclónicas, de ausência de nebulosidade e consequentemente sem ocorrência de precipitação são potenciadoras dos contrastes termohigrométricos espaciais locais, tendo sido, por isso, privilegiadas na escolha dos dias de observação.

Nas duas campanhas itinerantes seleccionadas, tanto no inverno como no período estival, verificaramse grandes contrastes termohigrométricos espaciais. 0 vento, partindo de outra observação, efectuada no inverno, traduziu um contraste espacial bastante nítido.

As situações sinópticas, nas noites em análise, foram as seguintes

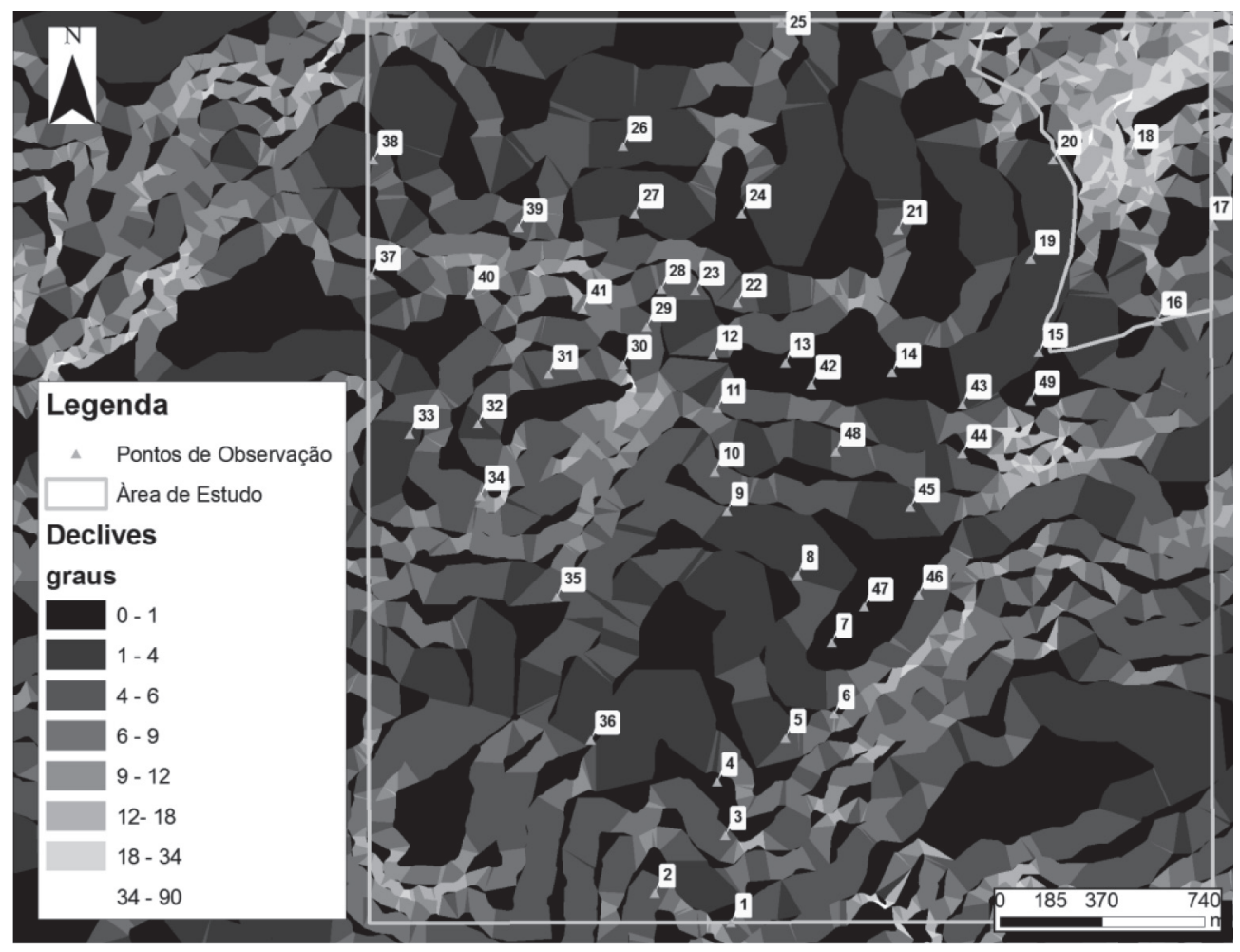

Figura 4

Declives da cidade de Mangualde

Fonte: Cartas altimétricas 189 e 190 


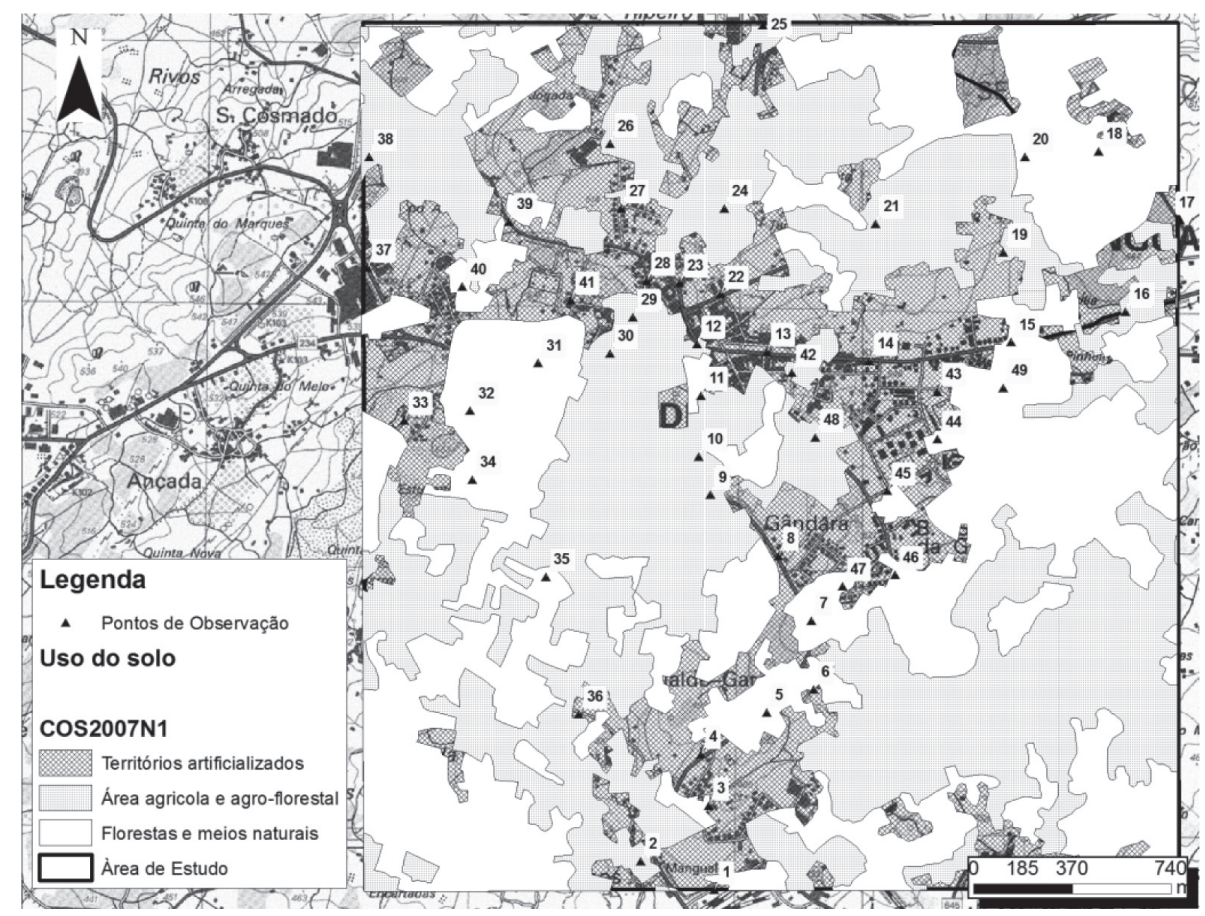

Figura 5

Uso do solo na cidade de Mangualde

Fonte: Cos, 2007

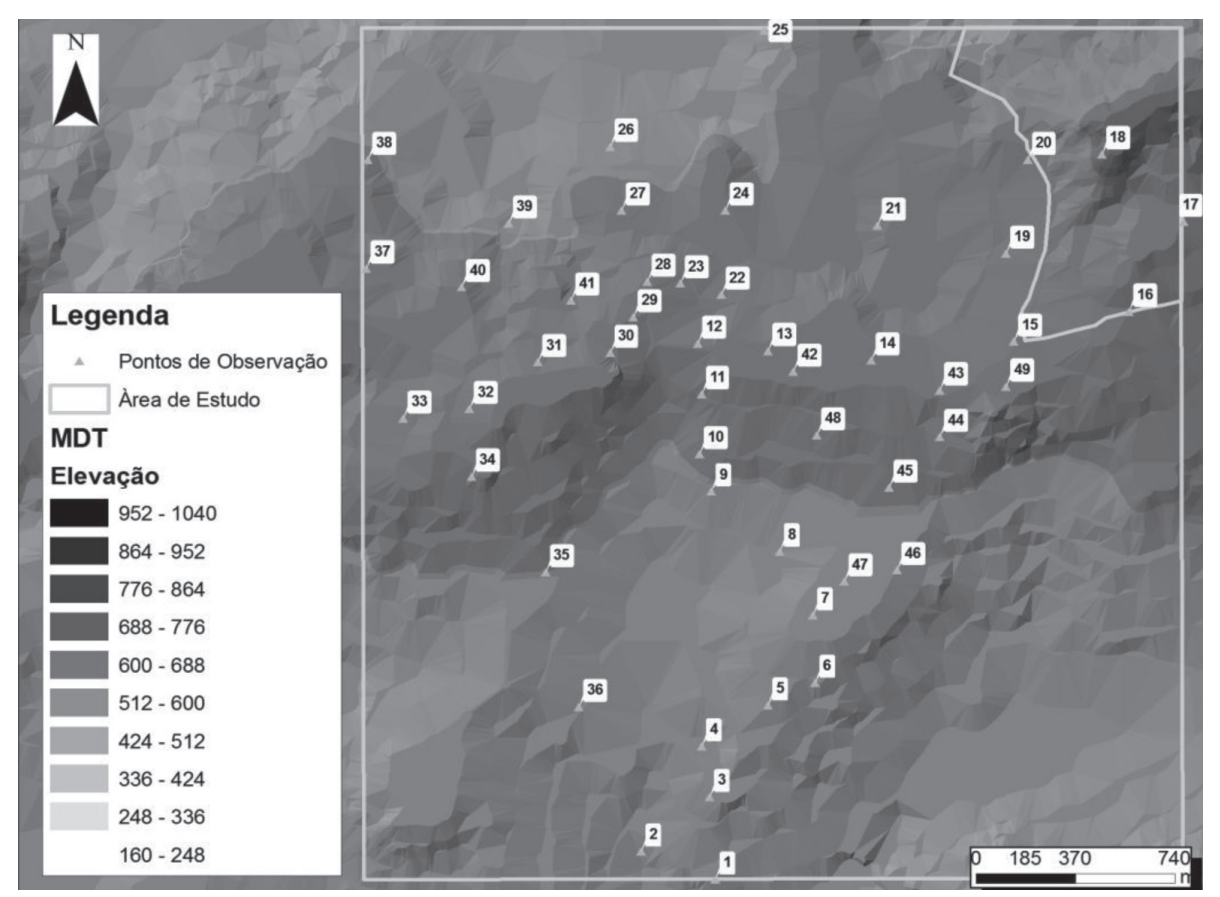

Figura 6

Topografia da cidade de Mangualde

Fonte: Cartas altimétricas 189 e 190 
Quadro I

Dias das observações invernais e estivais

\begin{tabular}{|l|l|l|}
\hline Variáveis climáticas & Época invernal & Época estival \\
\hline Temperatura e HR\% & $05 / 02 / 2011$ & $30 / 06 / 2011$ \\
\hline Vento & $22 / 01 / 2011$ & \\
\hline
\end{tabular}

Quadro II

Características dos pontos de observação

\begin{tabular}{|c|l|}
\hline Pontos & \multicolumn{1}{|c|}{ Características do uso do solo } \\
\hline 18 & Área florestal e verde sobre elevada, Vegetação: (arbórea, arbustiva e herbácea) \\
\hline $10,12,13,14,22,23,24,25,28,29,30,37,38,44,45,47$ & Área residencial, comercial e industrial, $>2$ pisos \\
\hline $1,2,3,4,5,7,8,15,16,17,19,26,27,31,33,40,41,42,46,49$ & Área residencial e comercial, $<2$ pisos \\
\hline $9,11,20,21,34,35,36,39$ & Áreas agrícolas ou em abandono (hortícolas e estrato herbáceo) \\
\hline $6,32,34,48$ & Área florestais (estrato arbóreo e arbustivo) inclusive arvores de fruto \\
\hline
\end{tabular}

- Dia 05-02-2011 - Portugal sob acção de um fluxo de Leste, associado a um anticiclone Iberomediterrâneo (Am) centrado no interior da Península Ibérica. Fluxo de fraca intensidade e com temperaturas agradáveis para a época.

- Dia 30-06-2011 - Anticiclone atlântico misto prolongando-se pela Europa Ocidental (Ao), centrado a NW do arquipélago dos Açores, conjugado com um vale térmico ibérico, canalizando para Portugal uma massa de ar polar continental (Pc), transportada por uma circulação de Leste.

- Dia 22-01-2011 - Acção de um fluxo forte de Nordeste, associado à circulação conjunta de um anticiclone que se centrava nas Ilhas Britânicas, estendendo-se em crista até ao Norte de Portugal, e de uma depressão centrada no continente europeu e de outra no arquipélago da Madeira.

\section{Contrastes e padrões topoclimáticos}

\subsection{Contrastes espaciais}

Dia 5 de Fevereiro de 2011 - O último dia das observações invernais pautou-se pela sua elevada variação térmica espacial, registando uma forte estabilidade atmosférica e vento fraco ou situação de calma. Foi também neste dia que se verificou a temperatura média mais elevada $6^{\circ} \mathrm{C}$, a temperatura mais alta, de $9,9^{\circ} \mathrm{C}$, registou-se no ponto de maior altitude, o ponto 18 (Senhora do Castelo). A temperatura mais baixa registada nesta noite foi de $2,6^{\circ} \mathrm{C}$, num dos pontos de menor cota, o ponto número 39 (Estrada da Roda). A variação térmica espacial nesta noite foi particularmente intensa, registando $7,3^{\circ} \mathrm{C}$ de contraste espacial total, fortemente relacionado com as condições de forte inversão térmica por arrefecimento irradiativo do ar pela base.

A humidade relativa média registada neste dia foi de $63,9 \%$. A humidade relativa máxima registada foi de 72\% nos pontos 14, 16 e 49 (Rua Azurara da Beira, EN 16 e Bairro do Modorno, respectivamente). A humidade relativa mínima registada foi de $55 \%$ para o ponto 35 (Área agrícola superior à aldeia de Cubos). 0 contraste higrométrico espacial total foi, então, de $17 \%$.

Dia 30 de Junho de 2011 - Este dia foi caracterizado pela ausência de vento e a temperatura média dos 49 pontos foi de $19,9^{\circ} \mathrm{C}$. A temperatura mais baixa registada foi de $16,2^{\circ} \mathrm{C}$ no ponto número 2 (Largo da Santa Marta, Cubos) e a temperatura mais elevada observada foi de $22,7^{\circ} \mathrm{C}$ no ponto 37 PSA (Peugeot/ Citroën). A amplitude térmica neste dia foi de $6,5^{\circ} \mathrm{C}$, sendo a mais elevada da amostra estival.

A humidade relativa média registada foi de $50,1 \%$. O valor máximo detectado foi de $62 \%$ nos pontos 22 e 23 (Avenida da Senhora do Castelo e Rua Sebastião de Alcântara) e o menor valor registado correspondeu aos pontos 48, 36 e 35 (Quinta do Alpoim, área agrícola superior à aldeia de Cubos), onde a humidade relativa foi de $44 \%$. A amplitude higrométrica total entre os diferentes pontos de registo, neste dia, foi de $18 \%$.

Dia 22 de Janeiro de 2011 - O vento, em particular nesta noite, fazia-se sentir com velocidade moderada de Nordeste, tendo-se observado a rajada máxima no ponto 18 (Senhora do Castelo) com $8,6 \mathrm{~km} / \mathrm{h}$, sendo este o pondo de maior altitude $(628 \mathrm{~m})$. Facto importante é a ausência de inversão térmica pela destruição da estratificação térmica estável por turbulência, imposta pela velocidade do fluxo na camada de atrito, e a baixa humidade relativa. 


\subsection{Padrões termohigrométricos invernais}

0 dia 5 de Fevereiro foi o dia em que a amplitude térmica espacial foi mais elevada (Figura 7). 0 ponto de maior altitude destaca-se da restante envolvência. A Senhora do Castelo é, assim, o local com a temperatura mais elevada. A ilha de calor, partindo do centro da cidade, estende-se por todo o sector Sudeste da área de estudo, sendo esta uma situação semelhante à do dia 16 de Janeiro de 2011. A Norte, a manifestação das temperaturas mais baixas é, nesta noite, mais extensa. A Sul, uma pequena ilha de frescura observa-se na aldeia de Cubos.

O dia 5 de Fevereiro de 2011 foi o que registou, também, uma das maiores amplitudes higrométricas espaciais nocturnas. Bem como um padrão higrométrico diferente dos anteriores (Figura 8). A baixa humidade relativa que se localiza a Norte da aldeia de Cubos prolonga-se para Sul, substituindo a ilha de humidade que se estabelecera ali anteriormente. Ocupando todo o sector Sul, liga-se à ilha de secura da área das Es- colas, formando, agora, uma "língua de secura", que contrasta com o aumento higrométrico que tem origem na Senhora do Castelo e se prolonga até ao centro urbano da cidade de Mangualde, perdendo intensidade em direcção a Sudoeste.

\subsection{Padrão termohigrométrico estival}

O dia 30 de Junho de 2011 aquando da primeira observação estival, revelou um contraste térmico significativo (Figura 9). A concentração de calor no centro urbano da cidade de Mangualde é proeminente, contudo, estende-se para Oeste para a área da PSA (Peugeot/ Citroën), assim como para Sudeste, envolvendo a área das Escolas e o Bairro da Gândara. A ilha de calor é, então, bem visível no centro urbano e restringe-se às áreas de maior urbanização. A Norte, a Sul e a Sudoeste da cidade de Mangualde, desenvolvem-se áreas frias, fora do perímetro urbano da cidade e em posição topográfica deprimida, destacando-se o Largo de Santa Marta (Cubos), onde o ar mais frio se acumula com maior

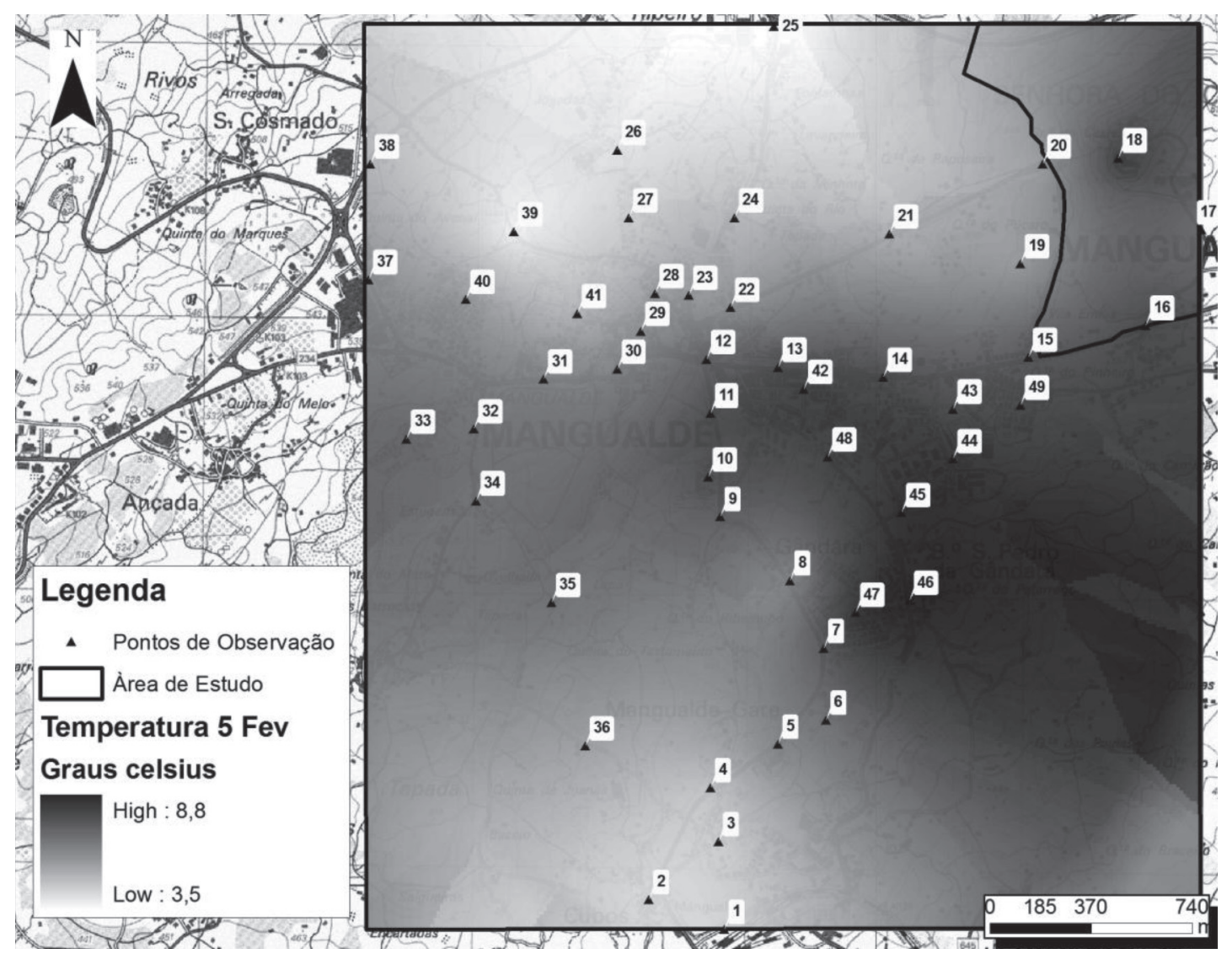

Figura 7

Campo térmico invernal

Elaboração própria 


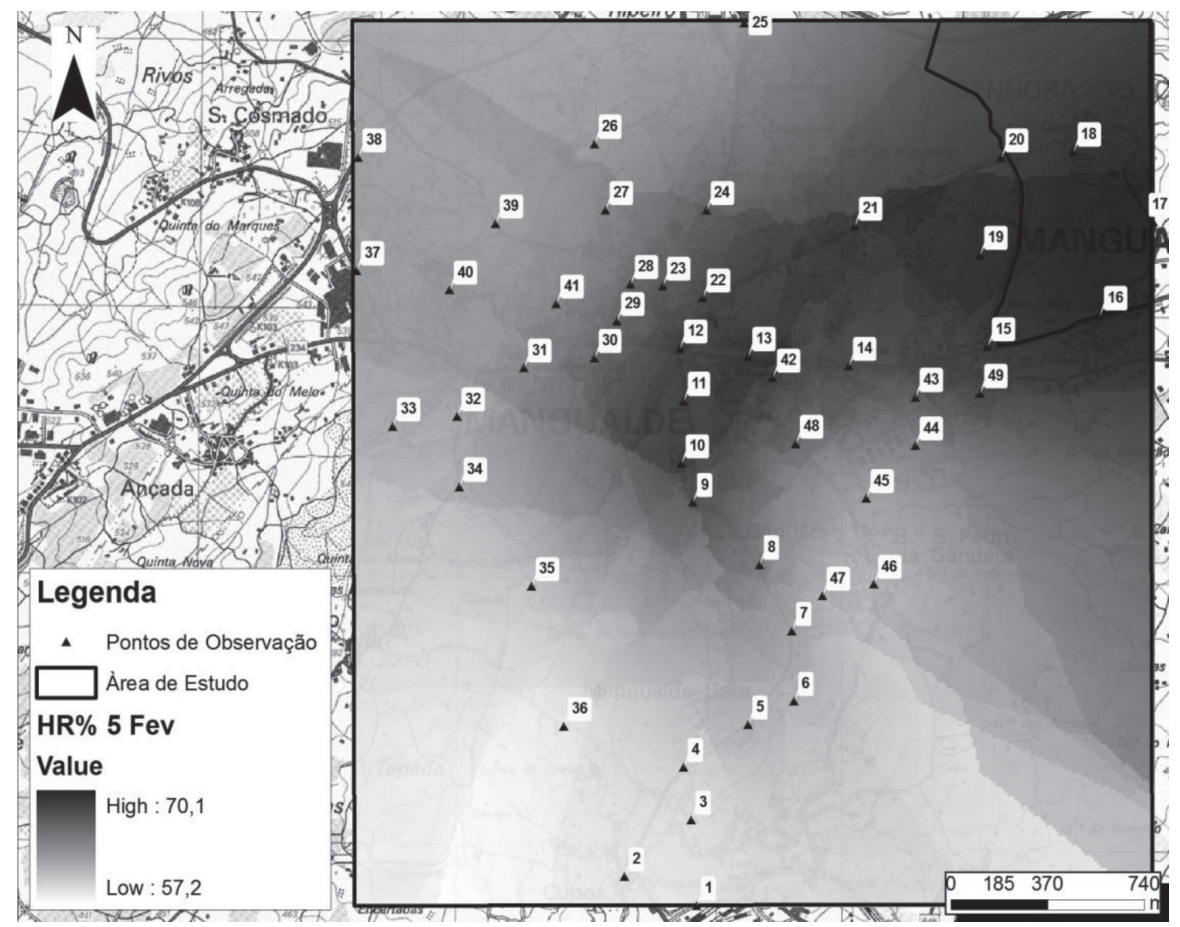

Figura 8

Campo higrométrico invernal

Elaboração própria

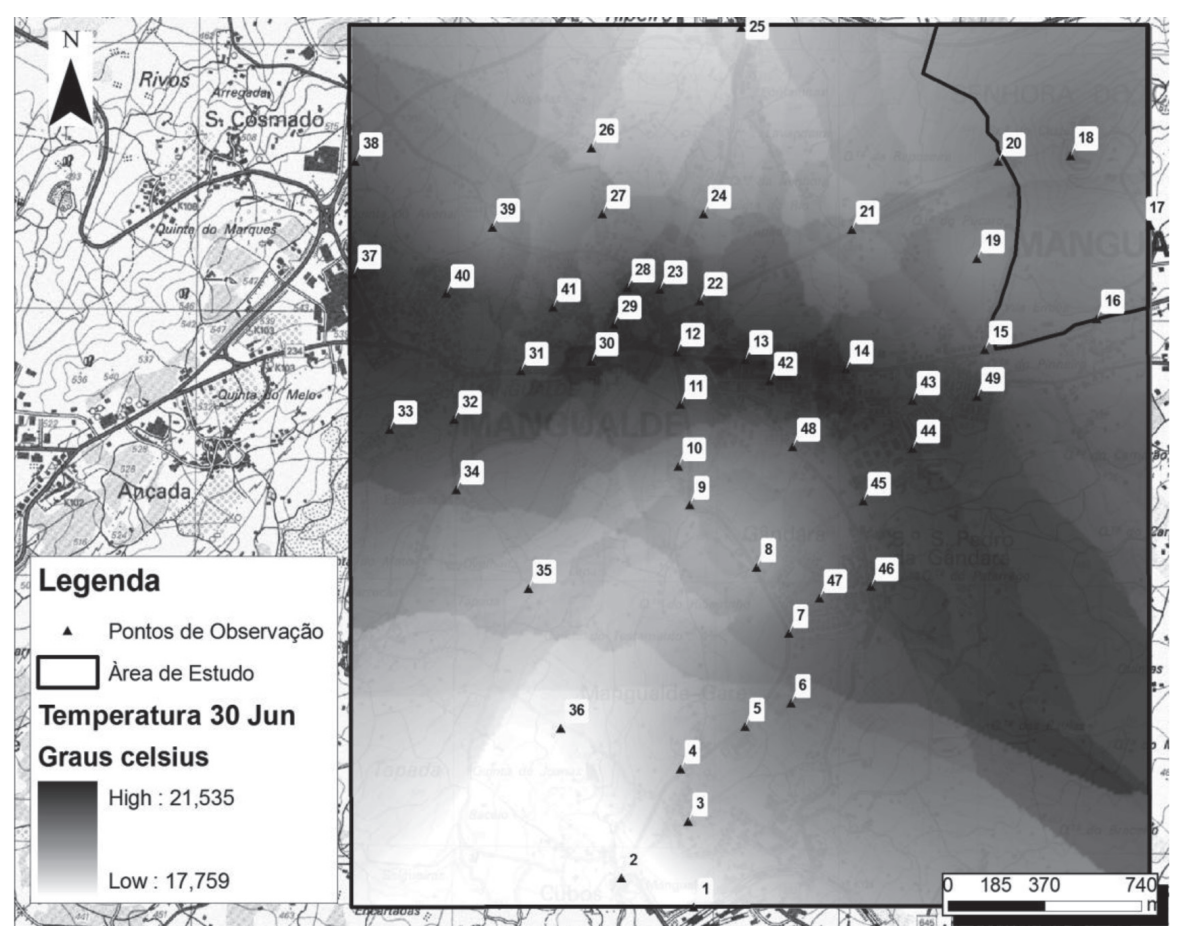

Figura 9

Campo térmico estival

Elaboração própria 


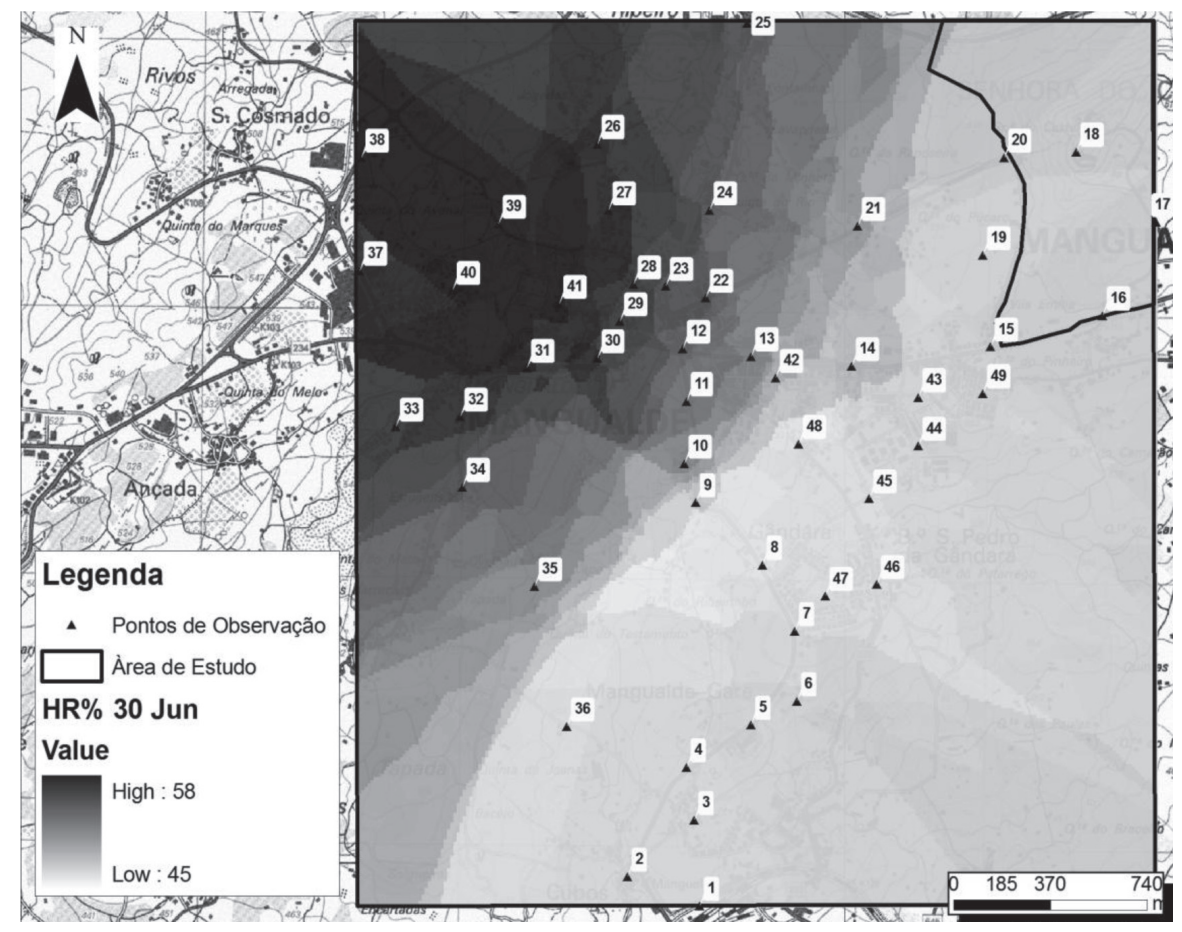

Figura 10

Campo higrométrico estival da cidade de Mangualde

Elaboração própria

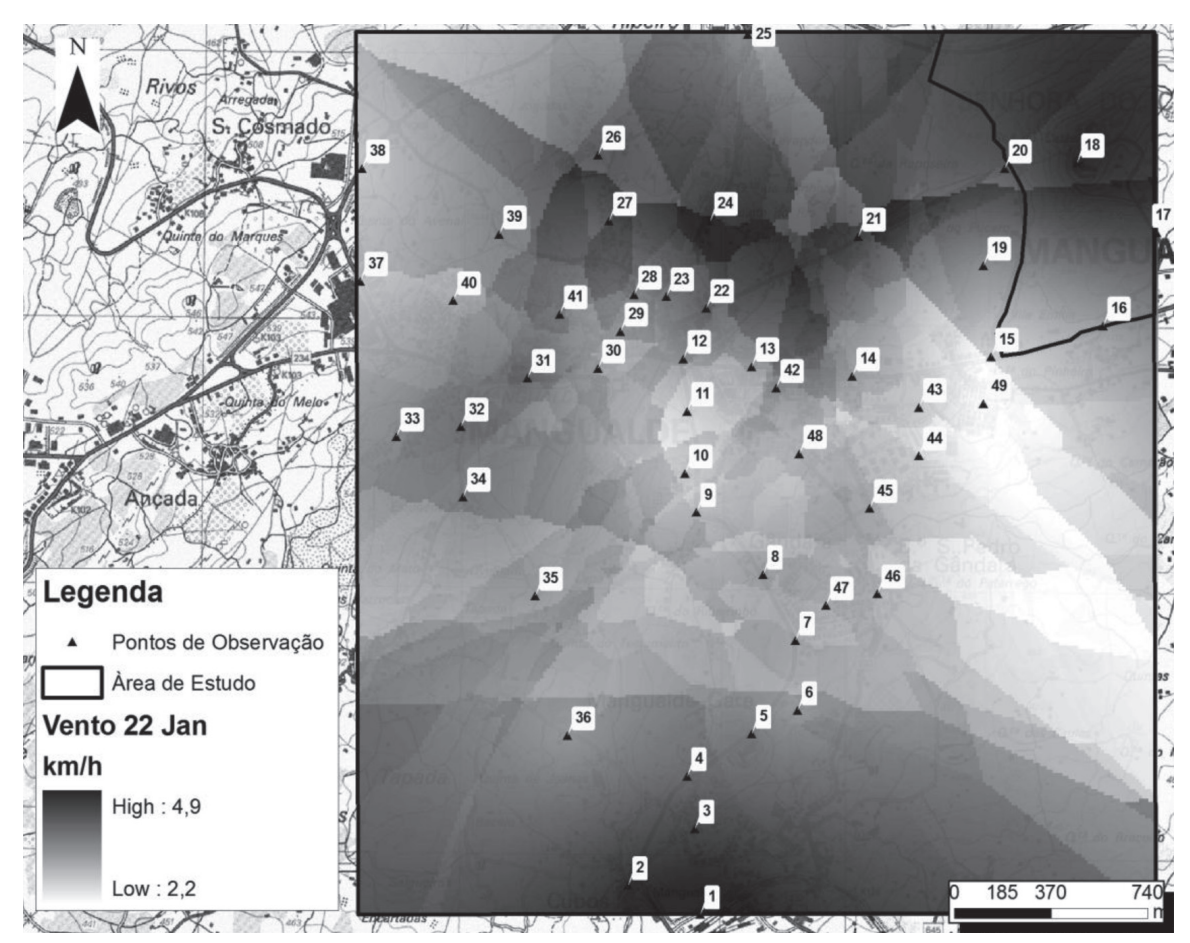

Figura 11

Padrão de vento de Nordeste na cidade de Mangualde

Elaboração própria 
intensidade, progredindo para Norte. Essa progressão é dificultada pelo declive Sul da vertente, pronunciando ainda mais a ilha de calor no centro da cidade.

Os contrastes higrométricos revelam características peculiares (Figura 10). A divisão entre o Este, mais seco e o Oeste, mais húmido, é revelador dessa peculiaridade. A humidade relativa mais elevada, proveniente de Noroeste, invade o centro urbano da cidade no seu flanco ocidental. Estende-se para Norte (Pingo Doce) e para o Bairro da Nossa Senhora da Imaculada Conceição. A humidade relativa assume os seus menores valores nos sectores Nordeste, Este e Sudeste, nomeadamente na Senhora do Castelo, no centro urbano da cidade, na área das Escolas, no Bairro da Gândara e na aldeia de Cubos, que correspondem, assim, às áreas mais secas deste percurso de observação.

\subsection{Padrão de vento invernal}

O dia 22 de Janeiro de 2011, o segundo dia em que se registou vento, neste caso de Nordeste (rumo mais frequente no Inverno), foi aquele em que a velocidade do vento foi mais elevada. Com esta observação foi possível verificar um maior incremento da velocidade do vento a Norte e a Sul, denotando-se, assim, muito bem, os limites aerodinâmicos espaciais (Figura 11). A Norte, com o adensamento da malha urbana que reduz significativamente a velocidade do vento pelo elevado efeito de atrito e a Sul, embora também em locais com elevada densidade urbana, a velocidade do vento intensifica-se. A malha urbana densa é composta por moradias individuais, com espaços intersticiais e de volumetria reduzida, contrastando com a maior densidade, volumetria e compactação urbana do centro de Mangualde. Assim, o espaço construído, de menor dimensão, localizado na área suburbana, não representa um obstáculo às circulações de Nordeste.

\section{Conclusão}

Os contrastes termohigrométricos e de vento, na cidade de Mangualde, estão muito dependentes das circulações sinópticas e da sazonalidade do clima Mediterrâneo. Na época invernal, sob céu limpo e vento fraco ou calma, a topografia desempenha um papel fundamental nos contrastes espaciais, térmicos, higrométricos e de vento. 0 desenvolvimento de inversões térmicas nocturnas por arrefecimento do ar pela base, são muito frequentes na época invernal em Mangualde. Assim, as temperaturas dos locais com cota mais elevada são aqueles que, frequentemente, registam maiores temperaturas. No entanto, o centro urbano também é caracterizado por uma temperatura mais elevada relativamente ao espaço envolvente, o que se traduz por uma ilha de calor localizada no centro da cidade, com prolongamento para Sudeste. A ocupação urbana do solo, a alteração do coberto vegetal e a concentração das actividades antrópicas no centro da cidade de Mangualde, promovem a ilha de calor urbana. Na época estival, a ilha de calor mantém-se com as mesmas características, prolongando-se para Oeste, e o factor topografia perde importância relativamente aos factores relativos às características da ocupação do solo.

Os contrastes higrométricos são, nas duas observações analisadas, opostos. Na época invernal, as áreas mais húmidas são as áreas de cota mais elevada, onde se destaca a Senhora do Castelo, a Nordeste da cidade, prolongando-se para Sudoeste, para o centro urbano, onde se forma uma ilha de humidade.

$\mathrm{Na}$ época estival o centro urbano tem tendência para apresentar uma secura maior que o espaço envolvente, formando-se com regularidade uma itha de secura.

Em todas as observações, tanto de Verão como de Inverno, a área das escolas revela uma secura evidente relativamente à área envolvente, constituindo-se como uma ilha de secura, que com as temperaturas invernais baixas e a humidade relativa reduzida, induzida pela escassez de vegetação e pela elevada impermeabilização do solo, tornam este, um dos espaços mais desconfortáveis, do ponto de vista bioclimático, da área de estudo.

Tendo sido possível observar a velocidade do vento em apenas um percurso de medição, na época invernal, onde o rumo é predominantemente de Nordeste, verificou-se que o perímetro urbano corresponde ao limite aerodinâmico da cidade. 0 atrito da malha urbana reduz substancialmente a velocidade do vento dentro da cidade. Pelo contrário, a Senhora do Cas telo é o local mais exposto e bioclimáticamente mais desconfortável, na época invernal. Na época estival, a mesma exposição atenua o desconforto bioclimático, mitigando o stress térmico, principalmente aquando de ondas de calor e de noites tropicais.

\section{Referências bibliográficas}

Alcoforado, J. M. (1988) - "O clima da região de Lisboa - Vento, insolação e temperatura". Dissertação de Doutoramento em Geografia Física apresentada à Faculdade de Letras da Universidade de Lisboa, pp. 543. 
AlCoforado, M. J. (1999) - "Aplicação da Climatologia no Planeamento Urbano. Alguns apontamentos". Finisterra, XXXIV, 67, 68, pp. 63-84.

AlCOFORAdo, M. J. e VIEIRA, H. (2004) - "Informação climática nos Planos Directores Municipais de concelhos urbanos. Possível articulação com o planeamento em Lisboa". Sociedade e Território - Revista de Estudos Urbanos e Regionais, 37/38, pp. 103-118.

alcoforado, M. J.; Alegria, M. F.; Ramos-Pereira, A. e Sirgado, C. (2009) - "Domínios Bioclimáticos em Portugal". Instituto de Geografia e Ordenamento do Território, Universidade de Lisboa, pp. 17-35

Ferreira, A. B. (1978) - Planaltos e Montanhas do Norte da Beira. Estudo de Geomorfologia. Centro de Estudo Geográficos de Lisboa.

Marques, D.; Ganho, N. e Cordeiro, A. (2008) - "Clima Local e Ordenamento Urbano - O exemplo de Coimbra". Cadernos de Geografia, 26/27, 2007/2008, pp. 313323.

Marques, D.; Ganho, N. e Cordeiro, A. (2009) - "O contributo de estudos climáticos à escala local para o ordenamento urbano - O exemplo de Coimbra (Portugal)". Actas (em CD) do $1^{\circ}$ Congresso de Desenvolvimento Regional de Cabo Verde, $2^{\circ}$ Congresso Lusófono de Ciência Regional, $3^{\circ}$ Congresso de Gestão e Conservação da Natureza e $15^{\circ}$ Congresso da Associação Portuguesa de Desenvolvimento Regional (APDR), Cidade da Praia, Cabo Verde, pp. 33943415.
Ganho, N. (1995a) - "A ilha de calor de Coimbra - Resultados de observações itinerantes de temperatura no interior do tecido urbano". Actas do VI Colóquio Ibérico de Geografia, Porto, pp. 911-920.

Ganho, N. (1995b) - "La isla de calor de Coimbra bajo diferentes condiciones de tiempo de Verano". Estudios Geográficos, LVI, 219, pp. 285-317.

Ganho, N. (1995C) - "A ilha de calor de Coimbra sob diferentes condições de tempo de Verão". Territorium, 2, pp. $33-50$.

Ganho, N. (1998) - O Clima Urbano de Coimbra. Estudo de Climatologia local aplicada ao ordenamento urbano. Dissertação de Doutoramento em Geografia Física apresentada à Faculdade de Letras da Universidade de Coimbra, Coimbra, $551 \mathrm{p}$.

Ganho, N. (1999) - "Clima Urbano e a Climatologia Urbana. Fundamentos e aplicação ao ordenamento urbano". Cadernos de Geografia, 18, pp. 97-127.

Melo, H. M. (2011) - O Clima de Mangualde. Contrastes Topoclimáticos, Efeitos Bioclimáticos e Aplicação ao Ordenamento Urbano. Dissertação de Mestrado em Geografia Física apresentada à Faculdade de Letras da Universidade de Coimbra, Coimbra, 141p.

OKE, T. R. (1987) - Boundary Layer Climates. Methuen, London, $372 \mathrm{p}$.

Ribeiro, O. (1949) - Le Portugal Central. Livret-Guide de l'Excursion C, Congrés Internacional de Géographie, Lisbonne. 